\title{
Even Americans pre-aspirate
}

\author{
Míša Hejná, Kamil Kaźmierski ${ }^{2}$ and Wenyu Guo ${ }^{1}$ \\ ${ }^{1}$ Aarhus University $\mid{ }^{2}$ Adam Mickiewicz University
}

This paper focuses on a phenomenon known as pre-aspiration, defined as a period of glottal friction found in the sequences of sonorants and phonetically voiceless obstruents, as in hit [ $\left.\mathrm{hr}^{\mathrm{h}} \mathrm{t}\right]$, hat $\left[\mathrm{h}^{\mathrm{h}} \mathrm{h}_{\mathrm{t}}\right]$, hiss [ $\left[\mathrm{hr}^{\mathrm{h}} \mathrm{s}\right]$, and cash $\left[\mathrm{k}^{\mathrm{h}} \int\right]$. Pre-aspiration has been reported in North American English (Clayards and Knowles 2015); however, there are no systematic studies of pre-aspiration in this part of the English-speaking world. Our study therefore considers the following main questions. 1. Is pre-aspiration present in American English and how frequent is it? 2. Does it vary by region? We also map variation related to speaking task, sex, and a range of language-internal factors. Our analyses of data from the Nationwide Speech Project Corpus (Clopper and Pisoni 2006) confirm that pre-aspiration is a feature of American English, with rates of application reaching between o-2o percent, depending on the region and the task. Furthermore, the more formal the task, the higher the rate of pre-aspiration application.

Keywords: pre-aspiration, American English accents, phonetics, corpus phonology, variation

\section{Introduction}

\subsection{Pre-aspiration as an areal phenomenon}

Pre-aspiration is a period of (most typically) glottal friction found in sequences of sonorants and phonetically voiceless obstruents, such that the words puppy, shit, and lesson, when pronounced with pre-aspiration, would be transcribed as

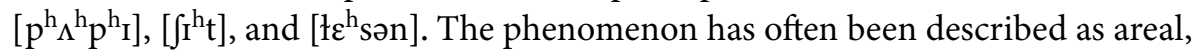
occurring primarily in Celtic and Scandinavian languages in Northern Europe (Helgason 2002: iii; Morris 2010; McKenna 2013; but see Hejná (2015:25-31). Docherty and Foulkes (1999) were the ones to first explicitly study the phenomenon in English. More recently, pre-aspiration has been reported in fortis obstruents in an increasing number of varieties of English found in the UK 
and Ireland (Jones and Llamas 2003; Watson 2007:171, 183, 201; Gordeeva and Scobbie 2010, 2013; Morris 2010; Hejná 2015, 2016a; Hejná and Scanlon 2015; Kettig 2015; Clayton 2017; Hejná and Jespersen 2019), which supports the view of pre-aspiration as a northern European areal phenomenon. However, it has recently also been incidentally reported in Australian English ( $\mathrm{Su} 2007$; Jones and McDougall 2009:269, 271-272, 279; Tait and Tabain 2016), North American English (Clayards and Knowles 2015; Hejná and Jespersen 2019), and New Zealand English (Fiasson 2016). More specifically for North American English, Clayards and Knowles (2015) report that pre-aspiration can occur in the context of /s/ and $/ \mathrm{J} /$, which are the two fortis obstruents the authors focus on. In addition, Hejná and Jespersen (2019) report a small number of instances of pre-aspirated /s/ and /t/ in a speaker of Canadian English (no other fortis obstruents were investigated), although it is practically non-existent in the speaker's / $t$ /, even where this $/ t /$ is not realized as a flap (e.g. as in lot [lat]). Importantly, many of the studies of British English pre-aspiration are exploratory in nature, i.e. they attest the presence of pre-aspiration in the variety in question, but do not provide us with an understanding of the factors that affect it and therefore what functions it might have. A couple of more systematic studies have been carried out in the recent past as well, focusing on English varieties in the UK (Docherty and Foulkes 1999; Morris 2010; Hejná 2015; Clayton 2017). This is also the case for New Zealand English (Fiasson 2016). Nevertheless, there is no systematic study of the phenomenon in North American English. This study aims to address this gap by asking the following primary questions:

- RQ 1: How frequent is pre-aspiration in American English?

- RQ 2: Is American English pre-aspiration restricted to specific regions?

A study of pre-aspiration in American English also offers tackling two other, broader questions. The first is related to the comparability of pre-aspiration studies (Section 1.2) and the second to the cross-linguistic constraints on preaspiration (Section 1.3). We turn to a discussion of these broader aspects of pre-aspiration in what follows.

\subsection{Comparability of studies of pre-aspiration in English dialects}

Although studies of English pre-aspiration have been growing in number over the last twenty years (see the references in Section 1.1), it is not necessarily easy or even possible to directly compare the results available for different varieties of the language. This is because not all English pre-aspiration studies employ the same speaking tasks, and when they do, the linguistic material may still present some structural differences, such as the inclusion of only plosives (e.g. as in 
back and bat; for instance Docherty and Foulkes 1999; Morris 2010; Fiasson 2016) or only fricatives (e.g. as in grass and leash; for instance Gordeeva and Scobbie 2010; Clayards and Knowles 2015). When studies target both plosives and fricatives, they do not always focus on the same places of articulation. For example, in their study of Middlesbrough English pre-aspiration, Jones and Llamas (2003) analyse word-final /t/, /s/, and / $/$. Another difficulty lies in the fact that while some studies use sociolinguistic interviews (Docherty and Foulkes 1999), others rely on word-list data comprising words read in isolation (e.g. Morris 2010; Clayton 2017) or in carrier sentences (e.g. Hejná and Scanlon 2015). Furthermore, the carrier sentences typically used are of a rather diverse nature. Some are constructed to enhance a voicing contrast (e.g. I say bus, and not buzz.; Gordeeva and Scobbie 2010), while others are more neutral in this respect (e.g. I say cap again.; Hejná 2015, 2016a).

While speaking tasks may be related to social aspects or formality, there is also a possibility of language-internal, prosodic differences associated with the different tasks typically used. Thus, Clayards and Knowles (2015), and Hejná and Jespersen (2019) find that pre-aspiration is more frequent and possibly longer in duration in prosodically more prominent contexts. Words read in isolation and carrier sentences of the Say $X$ again type are bound to lead to production with an increased prominence - unlike sociolinguistic interviews, which present contexts with richly variable degrees of prosodic prominence. Fiasson (2016) presents a notable exception in that he includes a range of speaking tasks. Interestingly, he finds that pre-aspiration is more frequent in word-list data than spontaneous speech in New Zealand English, which meshes well with the observation that environments that are more prominent will also exhibit more frequent (and longer) pre-aspiration.

Importantly, in most studies discussing pre-aspiration, the specific segmental and prosodic contexts were not selected with a systematic investigation of constraints on pre-aspiration in mind. This is either because the studies are the first ones that look into pre-aspiration in the varieties at hand, or because the aim of these studies is not directly related to pre-aspiration in the first place. The present study therefore aims to analyse pre-aspiration in American English (AmE) in a wider range of structural contexts, as well as a range of speaking tasks. This then motivates the following questions:

- RQ 3: Does AmE pre-aspiration occur in fortis fricatives /f, $\theta, \mathrm{s}, \mathrm{J} / \mathrm{as}$ well as fortis plosives $/ \mathrm{p}, \mathrm{t}, \mathrm{k} /$ ?

- RQ 4: Does pre-aspiration show variation by speaking task? More specifically, is pre-aspiration increasingly less frequent as one moves from word-list data to carrier sentences, reading passages, and finally (semi-)spontaneous speech? 


\subsection{Cross-linguistic constraints on pre-aspiration}

Morris and Hejná (2020) discuss universal constraints on pre-aspiration. These are related to the speaker's sex as well as language-internal factors, including the place of articulation of the pre-aspiration-inducing obstruent, vowel height, vowel duration, and vowel length. More specifically, it has been often observed that female speakers produce more frequent and/or longer pre-aspiration (see the references in Morris and Hejná 2020), with the exception of Halh Mongolian (Jatteau and Hejná 2018) and Italian (Stevens 2010), although the latter study presents a potential confound between sex and place of articulation of the obstruent. This motivates the following question:

- RQ 5: Do females pre-aspirate more frequently than males in AmE?

As also reviewed by Morris and Hejná (2020), pre-aspiration has been typically observed to be the most frequent and/or longest in duration with $/ \mathrm{k} /$, or $/ \mathrm{k} /$ and $/ \mathrm{t} /$, as opposed to /p/. In addition, vowel height correlates with pre-aspiration: the higher the vowel, the less frequent and the shorter the pre-aspiration. Long vowel contexts disprefer pre-aspiration cross-linguistically: long vowels are associated with less frequent and/or shorter pre-aspiration (and in some languages block pre-aspiration entirely). Vowel duration, on the other hand, shows a positive correlation with pre-aspiration: the longer the vowel phonetically, the more frequent and the longer the pre-aspiration. In order to situate AmE in pre-aspiration typology, we therefore also ask the following:

- RQ 6: Is pre-aspiration most likely to occur in the context of $/ \mathrm{k} /$ ?

- RQ 7: Is pre-aspiration more likely to occur with low/non-high rather than high/non-low vowels?

- RQ 8: Is pre-aspiration more likely to occur with phonologically lax rather than tense vowels? (Other pre-aspiration studies work with the concept of phonological length rather than laxness/tenseness.)

- RQ 9: Is pre-aspiration more likely to occur with phonetically longer vowels?

Finally, very little is known about lexical frequency effects on pre-aspiration crosslinguistically, or for individual pre-aspirating languages. Hejná (2015:55) reports no frequency effects on pre-aspiration rate of application and duration, based on the SUBTLEX-UK frequency rates. This is the only study of pre-aspiration we are aware of that looks into lexical frequency effects on pre-aspiration in a quantitative way. Nance and Stuart-Smith (2013:147) mention word-specific pre-aspiration duration effects in their Scottish Gaelic data, with the word Pàpa 'pope' "[showing] little or no voiceless pre-aspiration, [and] aca 'at them' [showing] most". The authors explain these patterns by appealing to lexical frequency 
effects: as members of a protestant community, their speakers use the word Pàpa "extremely infrequently" or even "avoid" using it (2013:147). Because so little seems to be known about lexical frequency effects on pre-aspiration, we also ask the following exploratory question:

- RQ 10: Does pre-aspiration correlate with lexical frequency in AmE?

\section{Materials and methods}

In this section, we first discuss how we quantified pre-aspiration. We then introduce the materials, and finally provide information about how the data was processed.

\subsection{Pre-aspiration}

Pre-aspiration was defined here as a period of voiceless (primarily) glottal friction, which is found in sequences of sonorants and phonetically voiceless obstruents, in line with other studies of the phenomenon (e.g. Ní Chasaide 1985; Kingston 1990; Nance and Stuart-Smith 2013; Hejná 2015, 2016a; Hejná and Jespersen 2019; Morris and Hejná 2020). Both the waveform and the spectrogram were used to identify the phenomenon as follows. Firstly, pre-aspiration manifests itself as a glottal fricative which lacks periodicity in the waveform and shows no voicing bar in the spectrogram (see Figure 1).



Figure 1. Identification of pre-aspiration in a plosive environment

Importantly, when induced by a plosive or an affricate (e.g. lack, latch), this glottal friction is followed by a closure. This distinguished pre-aspirated plosives 
and affricates from spirantized ones. When pre-aspiration is induced by a fricative (see Figure 2), further criteria have to be employed.

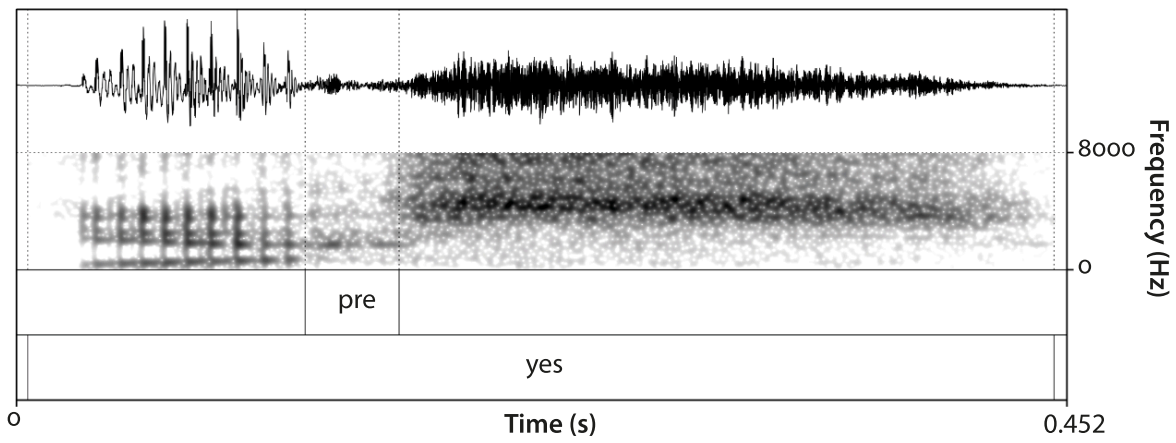

Figure 2. Identification of pre-aspiration in a fricative environment

In cases of $/ \mathrm{s} /$ and $/ \mathrm{J} /$, the glottal friction was relatively straightforward to distinguish from the oral friction of the fricatives due to its spectral properties: both $/ \mathrm{s} /$ and $/ \int /$ show increased energy in higher frequencies, unlike $/ \mathrm{h} /$. On the other hand, /f/ and $/ \theta /$ are spectrally more like $/ \mathrm{h} /$; however, the spectral properties of $/ \mathrm{h} /$ more closely resemble those of the preceding vowel, i.e. the formant structure in particular was decisive in such cases.

Another important issue to consider here is the definition of pre-aspiration. A phonetic phenomenon adjacent to pre-aspiration is local breathiness, which can be defined as an interval in the signal that shows periodicity, and thus voicing, as well as glottal friction, typically in higher frequencies (see for example Hejná $2016 \mathrm{~b}$ ). As follows from the definition of pre-aspiration adopted here, instances of local breathiness (e.g. Ní Chasaide 1985; Kingston 1990; Hejná 2015, 2016a; Hejná and Jespersen 2019; Morris and Hejná 2020) were excluded in the present study. This decision was made for two reasons. Firstly, our aim was to report cases that could be considered pre-aspirated by researchers adopting a range of preaspiration definitions. By focusing on only voiceless glottal friction, we are opting for the strictest identification of what is supposed to be a very rare phenomenon. Focusing only on voiceless pre-aspiration leaves no doubt that we are indeed reporting a phenomenon that most scholars would perceive as such. Secondly, but relatedly, analyses of local breathiness, which is excluded from our study, ultimately need to consider factors other than those of the obstruent in question, such as turn taking. This is because breathiness can also function as a cue to the end of a turn (di Napoli 2015), amongst other things. Such analyses are beyond the scope of the present study. 
It also needs to be mentioned that, in all cases, words with a word-medial / $t$ / were excluded right from the beginning. This was done because the phenomenon of /t/-flapping bleeds pre-aspiration in the corpus. However, it needs to be borne in mind that flapping contexts are available for pre-aspiration to apply in non-flapping varieties of English, which can therefore lead to higher rates of preaspiration application in those.

\subsection{Data processing}

The Nationwide Speech Project corpus, "designed to contain a large amount of speech produced by male and female talkers representing the primary regional varieties of American English" (Clopper and Pisoni 2006:633), and originally assembled for studying production and perception of dialect variation, including the effects of predictability and dialect region on vowel space reduction (Clopper and Pierrehumbert 2008), is the source of data for the present study. It comes with high-quality AIFF audio recordings and orthographic transcripts of a range of speaking tasks. The audio files were converted to the WAV format and downsampled to 22,050 Hz. During corpus creation, items for which "the participant misread an item or if there was any background noise while the participant read the item" (Clopper and Pisoni 2006: 641) were re-recorded. Although the corpus contains both the original and the corrected recordings, for the present study, only the corrected recordings were used. In the case of the interview data, the bundled transcripts were first manually aligned with audio on a breath-group level by the second author with the help of Praat (Boersma and Weenink 2018). Then, all transcripts were force-aligned on the word and phoneme levels with FAVE-aligner (Rosenfelder et al. 2014). All audio files and annotations were subsequently imported into LaBB-CAT (Fromont and Hay 2012), where an additional annotation layer with word-level phonemic transcriptions taken from the CMU Pronouncing Dictionary was generated. Based on this layer, the corpus was queried for the relevant contexts (see Section 2.3), and the relevant audio and annotation fragments were exported for manual coding of pre-aspiration.

\subsection{Materials}

The analyses are based on four of the different tasks available in the Nationwide Speech Project corpus (Clopper and Pisoni 2006) which were the only ones suitable for our research questions: a five-minute long sociolinguistic interview, a read passage (the Goldilocks passage), read sentences (high probability sentences), and a CVC word list (which only contains word-final obstruents). The sociolinguistic interview condition corresponds to the methodology employed in 
the now seminal pre-aspiration study of Tyneside English, England (Docherty and Foulkes 1999). The word-list data corresponds to the methodology employed by the vast majority of English pre-aspiration studies (see Section 1.2). The read sentences condition is presumably more formal than sociolinguistic interviews, but presents a more natural task than the word-list task. We describe each task separately here.

\subsubsection{Sociolinguistic interview data}

Within the "Interview speech" (spont) part of the corpus, we extracted all tokens with a fortis obstruent preceded by a vowel where this vowel carried stress, as, for example, in lesson, less, let, test, doctor, etc. This resulted in between 57 and 142 tokens per speaker $(S D=19.8)$, and 5,811 tokens in total.

\subsubsection{Read speech data}

The "Goldilocks passage" (gold) and the "High probability sentences" (hpspin) parts of the corpus were used for the analyses related to the read sentences context. We extracted the following words with a post-vocalic word-internal fortis plosive: aches, apple, ate, beak, bet, boat, brat, break, bright (x2), broken, caught, chat, checkers, chicken, chicks, chip, clock, coats, cooked, cops, croaking, cup, cut (x4), deep, deeper, deeply, doctor, dropped, eat, feet, flock (x2), lexical get, lexical got (x2), greet, hit, hot, keep (x2), knocked, loot, lots, maple, mat, meat, mop, open (x2), out (x4), ox, pet, picking, plot, sap, seats, second, set, sheep, shepherd, shepherds, sick, six, smoke, steep, stuck, super, take, thought, throat, ticking, took (x3), tracked, trap, unlock, walk (x2), walked, walking, white, wipe. This yielded 90 tokens per speaker and 5,400 tokens altogether. In addition, we also extracted the following words with a post-vocalic fortis fricative: bath, brief, calf, casts, cliff, dust, feast, glass, guests, host, house, lost, mouse, oath, off, peace, piece, pushed, Ruth, shuffled, slice, splash, task, thief, twist, wash. This provided us with 20 word-final and 11 word-medial fricative tokens per speaker and 1,860 tokens in total.

\subsubsection{Word list data}

The "CVC words" (cvc) part of the corpus was used for the analysis of the following words with a postvocalic fortis plosive: bite, boat, caught, cot, dock, doubt, gap, keep, lit, luck, poke, rip, tape, walk, wet. This provided us with 15 word-final tokens per speaker and 900 tokens in total. In addition, we extracted the following words with a post-vocalic fortis fricative: cough, death, math, rice, south, voice. This resulted in 6 tokens per speaker and 360 tokens in total. 


\subsection{Problematic contexts}

Certain words that meet the criterion of containing a sequence of a vowel and a fortis obstruent were excluded from the analyses. This was initially the case only where the presence of pre-aspiration could not be determined either due to inherent ambiguity or because of formal aspects to do with the processing of the acoustic signal. After excluding these ambiguous tokens, the overall number of tokens analyzed was reduced to 13,706 . Consequently, we removed tokens where the consonant was the affricate $/ \mathrm{t} f /$, (34/13,706 or 0.2 percent of observations). This was done because token counts were low for this affricate, making an estimation impossible and blocking the model from converging. This brought the overall number of observations to 13,672 (3,261 were followed by fricatives and 10,411 by plosives).

\subsection{Speakers}

The speakers $(N=60)$ of the Nationwide Speech Project corpus were recruited from Indiana University community. They were all native speakers of English, as were both parents of each speaker. There were 10 speakers ( 5 female and 5 male) from each of the six major dialect areas of the United States postulated by Labov, Ash and Boberg (2006): New England, Mid-Atlantic, the North, Midland, the South, and the West. All speakers had moved to Indiana no earlier than two years before the recording, and had lived in a single dialect area their entire lives prior to doing so. The age of the speakers at the time of the recording ranged from 18 to $24(S D=1.5)$. They were all white, from "middle or upper-middle class backgrounds" (Clopper and Pisoni 2006: 640).

\subsection{Annotation}

Initially, annotation of all four tasks was divided between the first and third authors. Then, we estimated token numbers which would be sufficient for the detection of differences between "poor" $(\kappa=0.4)^{1}$ and "fair to good" $(\kappa=0.6)$ inter-rater agreement. For this estimation, which tells us how many tokens we need to be able to reliably discriminate between poor and fair to good agreement, we used the kappaSize R package (Rotondi 2018). The token numbers calculated for the inspection of inter-rater agreement therefore were 294 for cvc, 906 for gold, 627 for hpspin, and 1,747 for spont. Subsequent calculations of the Cohen's kappa coefficients showed that agreement was poor $(\kappa=0.28)$ for gold, and fair

1. We employ qualitative labels for the magnitude of $\kappa$ after Fleiss (1981). 
to $\operatorname{good}(\kappa=0.49, \kappa=0.42)$ for hpspin and spont, respectively. Consequently, all tokens for these tasks were re-coded by the first author. For the CVC data, on the other hand, agreement was excellent $(\kappa=0.8)$, so no re-coding was necessary. The initial coding, with 71 percent of CVC tokens ( 765 ) coded by the third author and 29 percent (312) by the first author, was retained.

\section{Results}

We have analyzed a total of 13,672 tokens across four tasks: CVC words $(N=1,077)$, sentences $(N=5,797)$, narrative passage $(N=987)$, and interview speech $(N=5,811)$. Table 1 presents rates of pre-aspiration for each dialect region, broken down by task. Except for Midland, cvc is the task with the highest rate of pre-aspiration. The spont task consistently shows the lowest rates, dropping all the way down to o percent for the North.

Table 1. Absolute numbers and percentages of instances of pre-aspiration by dialect region by task

\begin{tabular}{|c|c|c|c|c|c|}
\hline Region & Task & Pre-aspiration & Region & Task & Pre-aspiration \\
\hline \multirow[t]{4}{*}{ West } & $\mathrm{cvc}$ & $36 / 180(20 \%)$ & \multirow[t]{4}{*}{ New England } & $\mathrm{cvc}$ & $19 / 177(11 \%)$ \\
\hline & gold & $17 / 166(10 \%)$ & & gold & $15 / 166(9 \%)$ \\
\hline & hpspin & $78 / 973(8 \%)$ & & hpspin & $55 / 969(6 \%)$ \\
\hline & spont & $43 / 939(5 \%)$ & & spont & $26 / 1,023(3 \%)$ \\
\hline \multirow[t]{4}{*}{ Mid-Atlantic } & $\mathrm{cvc}$ & $25 / 180(14 \%)$ & \multirow[t]{4}{*}{ North } & $\mathrm{cvc}$ & $27 / 180(15 \%)$ \\
\hline & gold & $12 / 166(7 \%)$ & & gold & $7 / 160(4 \%)$ \\
\hline & hpspin & $104 / 959(11 \%)$ & & hpspin & $95 / 963(10 \%)$ \\
\hline & spont & $24 / 899(3 \%)$ & & spont & o/955 (o\%) \\
\hline \multirow[t]{4}{*}{ Midland } & $\mathrm{cvc}$ & $15 / 180(8 \%)$ & \multirow[t]{4}{*}{ South } & $\mathrm{cvc}$ & $23 / 180(13 \%)$ \\
\hline & gold & $16 / 166(10 \%)$ & & gold & $10 / 163(6 \%)$ \\
\hline & hpspin & $74 / 970(8 \%)$ & & hpspin & $82 / 963(9 \%)$ \\
\hline & spont & $48 / 916(5 \%)$ & & spont & $19 / 1,079(2 \%)$ \\
\hline
\end{tabular}

Table 2 breaks the results down by the pre-aspiration-inducing obstruent. ${ }^{2}$

2. Note that $/ \theta /$ shows no instance of pre-aspiration. Whether or not these 19 cases are included in the analyses does not influence the models to an appreciable degree. 
Table 2. Absolute numbers and percentages of instances of pre-aspiration by phoneme

\begin{tabular}{lcc}
\hline \multicolumn{2}{l}{ Labials } & \\
\hline$/ \mathrm{p} /$ & $50 / 1,973$ & $3 \%$ \\
$/ \mathrm{f} /$ & $93 / 887$ & $10 \%$ \\
\hline
\end{tabular}

\section{Coronals}

$/ \mathrm{t} / \quad 86 / 4,567 \quad 2 \%$

/s/ $\quad 222 / 2,119 \quad 10 \%$

$/ \mathrm{S} / \quad 4 / 236 \quad 2 \%$

$/ \theta / \quad 0 / 19 \quad 0 \%$

\section{Dorsal}

\begin{tabular}{lll}
\hline$/ \mathrm{k} /$ & $415 / 3,871$ & $11 \%$ \\
\hline
\end{tabular}

58 of the 60 analysed speakers show some cases of pre-aspiration. Only in the North, where the rates are some of the lowest overall, are there two speakers who do not pre-aspirate at all. Speakers from the West show highest rates overall (Figure 3).

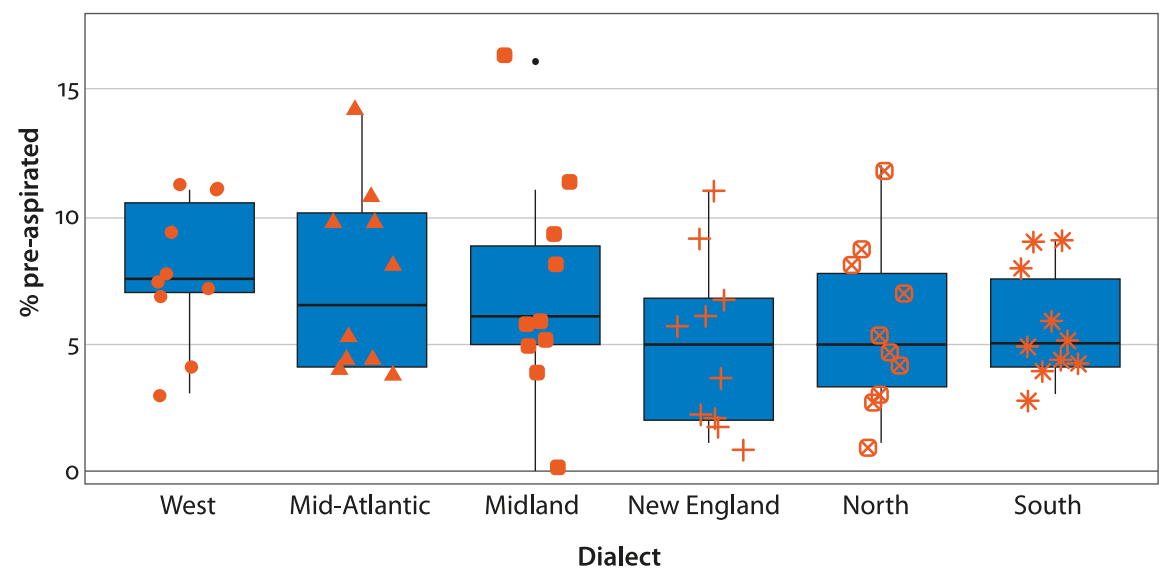

Figure 3. Rates of pre-aspiration for individual speakers, broken down by dialect region. Each point is one speaker. Jitter added to avoid overlap

To verify how systematic the trends observed in the data are, we modeled the presence of pre-aspiration with mixed-effects binomial logistic regression with the lme4 package (Bates et al. 2015) implemented in $\mathrm{R}$ ( $\mathrm{R}$ Core Team 2019). We included the following fixed effects: 
1. Task: Categorical predictor with four levels: cvc, gold, hpspin, spont (reference: $\mathrm{cvc}$, this being the most commonly used task in pre-aspiration studies).

2. Sex/Gender: Binary predictor with the following levels: female and male (reference: female). Sex/Gender information is contained in the corpus metadata.

3. Dialect: Categorical predictor with six levels: West, Mid-Atlantic, Midland, New England, North, South (reference: West).

4. Place and manner: Categorical predictor with the following levels: coronal plosive, coronal fricative, dorsal plosive, labial fricative, and labial plosive (reference: coronal plosive). This predictor encodes the manner and place of articulation of the pre-aspiration-inducing consonant.

5. Frequency: Continuous predictor, encoding the lexical frequency of the test word, based on SUBTLEX-US (Brysbaert \& New 2009). Raw frequency counts were log-transformed (natural logarithm), centered by subtracting the mean and standardized by dividing by one standard deviation. For lexical items present in the Nationwide Speech Project corpus but missing from SUBTLEX-US (31/781 [4 percent] word types, 234/13,672 [1.7 percent] word tokens), mean value was imputed.

6. Vowel height: Categorical predictor with three levels: non-high monophthongs /a $\supset \varepsilon æ \Lambda /$, high monophthongs /u $\mho$ o i I e/, diphthongs /ar a गI/ (reference: non-high monophthongs; these being the ones that crosslinguistically disprefer pre-aspiration, and considering that nothing is known about diphthongs and pre-aspiration in English).

7. Vowel class: Binary predictor with the following levels: tense /i a $\supset$ u e o ar a गI/ and lax /I $\varepsilon æ \Lambda$ / (reference: lax)

8. Word duration: Continuous predictor. Duration of each test word in ms (Centered and divided by one standard deviation, separately for groups of words with the same number of syllables).

9. Syllabic length: Binary predictor with the levels monosyllabic and polysyllabic (reference: monosyllabic).

10. Syllabic length ${ }^{*}$ Word duration: interaction term to capture the divergent predictions of word duration for monosyllables and polysyllables.

Additionally, we included a by-speaker and by-word random intercept to account for between-speaker and between-item variation in the likelihood of preaspiration. Categorical predictors were treatment-coded. The model converged with a Marginal $\mathrm{R}^{2}$ value of 0.35 and a Conditional $\mathrm{R}^{2}$ value of o.6. Standard deviation for the by-word random intercept was 1.6 whereas for the by-speaker random intercept it was 0.43 , showing a greater between-word than between-speaker 
variation in the likelihood of pre-aspiration. Model estimates for all fixed effects in the model are presented in Table 3 below.

Table 3. Coefficient table of all fixed effects in the model

\begin{tabular}{|c|c|c|c|c|c|}
\hline Term & & $\begin{array}{l}\text { Log- } \\
\text { Odds }\end{array}$ & $\begin{array}{l}\text { Std. } \\
\text { Error }\end{array}$ & $\begin{array}{c}\text { z- } \\
\text { value }\end{array}$ & $\mathrm{p}$ \\
\hline (Intercept) & & -3.00 & 0.45 & -6.64 & $<0.001^{\star *}$ \\
\hline \multirow[t]{3}{*}{ Task } & Gold & -0.59 & 0.31 & -1.90 & 0.057 \\
\hline & Hpspin & -0.93 & 0.33 & -2.83 & $0.005^{\star \star}$ \\
\hline & Spont & -1.26 & 0.36 & -3.48 & $<0.001^{\star * \star}$ \\
\hline Gender & Male & -0.16 & 0.19 & -0.86 & 0.393 \\
\hline \multirow[t]{5}{*}{ Dialect } & Mid-Atlantic & -0.07 & 0.33 & -0.21 & 0.834 \\
\hline & Midland & -0.23 & 0.33 & -0.68 & 0.494 \\
\hline & New England & -0.67 & 0.33 & -2.01 & $0.044^{*}$ \\
\hline & North & -0.50 & 0.33 & -1.52 & 0.129 \\
\hline & South & -0.37 & 0.33 & -1.13 & 0.256 \\
\hline \multirow[t]{4}{*}{ Place and manner } & $\begin{array}{l}\text { Coronal } \\
\text { fricative }\end{array}$ & 1.94 & 0.33 & 5.83 & $<0.001^{* * *}$ \\
\hline & Dorsal plosive & 2.57 & 0.32 & 7.99 & $<0.001^{* * *}$ \\
\hline & Labial fricative & 1.58 & 0.45 & 3.48 & $<0.001^{\star \star *}$ \\
\hline & Labial plosive & 0.15 & 0.43 & 0.36 & 0.719 \\
\hline \multirow[t]{2}{*}{ Vowel height } & High & -1.85 & 0.25 & -7.45 & $<0.001^{\star * *}$ \\
\hline & Diphthong & -1.61 & 0.44 & -3.68 & $<0.001^{\star \star \star}$ \\
\hline Vowel class & Tense & 0.16 & 0.24 & 0.66 & 0.507 \\
\hline Word duration & & 0.31 & 0.06 & 4.96 & $<0.001^{* * *}$ \\
\hline Syllabic length & Polysyllabic & -1.46 & 0.27 & -5.47 & $<0.001^{\star \star *}$ \\
\hline Frequency & & -0.39 & 0.14 & -2.84 & $<0.01^{\star *}$ \\
\hline $\begin{array}{l}\text { Word duration: Syllabic } \\
\text { length }\end{array}$ & Polysyllabic & -0.58 & 0.15 & -3.77 & $<0.001^{* * *}$ \\
\hline
\end{tabular}

Significance codes:

${ }^{\star * *} p<0.001 \quad{ }^{\star *} 0.001<p<0.01 \quad{ }^{\star} 0.01<p<0.05$

Since all categorical predictors are treatment-coded, the intercept $(-3.00$ logodds $=0.05$ probability) represents the estimated log-odds of pre-aspiratation when all categorical predictors are held at their reference levels, i.e. for the cvc 
task, for female speakers in the West dialect area, for the coronal plosive, nonhigh and lax vowels in monosyllabic words. Log-odds values for particular predictor levels shown in the table illustrate the difference in log odds of that level compared to the reference level. Since the continuous predictors were centered and standardized, the intercept value is for words of average duration and of average frequency. Their coefficients indicate the change to the intercept when they (word duration and lexical frequency) rise by one standard deviation. The coefficients for task show a decreasing likelihood of pre-aspiration from cvc (reference) through gold $(b=-0.59, p=0.057)$, hpspin $(b=-0.93, p=0.005)$, to spont $(b=-1.26, p<0.001)$, pointing to a systematic effect of the level of formality. The effect of sex/gender has not reached significance $(b=-0.16, p=0.393)$. As for the effect of dialect region, while all other regions show lower predicted preaspiration rates than the West, only for New England is this difference significant $(b=-0.67, p=0.044)$. Compared to the coronal plosive $/ \mathrm{t} / \mathrm{-}$ reference level for place and manner, coronal fricatives $/ \mathrm{s}, \theta, \mathrm{J} /$ are more likely to induce preaspiration $(b=1.94, p<0.001)$, as is the dorsal plosive $/ \mathrm{k} /(b=2.57, p<0.001)$ and the labial fricative $/ \mathrm{f} /(b=0.15, p<0.001)$. The labial plosive $/ \mathrm{p} /$ does not differ significantly from the coronal plosive $(b=0.15, p=0.719)$. Considering vowel height, pre-aspiration is less likely for both high vowels $(b=-1.85, p<0.001)$ and diphthongs $(b=-1.61, p<0.001)$ than it is for non-high vowels. The difference between tense and lax vowels has not reached significance. Higher lexical frequency is correlated with a lower likelihood of pre-aspiration $(b=-0.39, p<0.01){ }^{3}$ For monosyllabic words, the longer the duration of the word, the higher the likelihood of pre-aspiration $(b=0.31, p<0.001)$. For mean word durations, being polysyllabic decreases the likelihood of pre-aspiration $(b=-1.46, p<0.001)$. Finally, an increase in word duration is correlated with an increase in the likelihood of pre-aspiration for monosyllables, but not for polysyllables $(b=-0.58, p<0.001)$. Figure 4 presents a summary of terms found to be significant.

\section{Discussion}

This study analyzed the frequency of occurrence of pre-aspiration in AmE with the use of the Nationwide Speech Project corpus (Clopper and Pisoni 2006). We

3. Certain high-frequency words (e.g. what, get, like, cf. Appendix A) were only present in the spontaneous speech data. Fitting a model to a dataset with all such "stopwords" removed (using the stopwords R package (Benoit et al. 2020)) gives largely unchanged results for most predictors, with the effect of lexical frequency going in the same direction, but being somewhat smaller $(b=-0.29, p=0.046)$. 

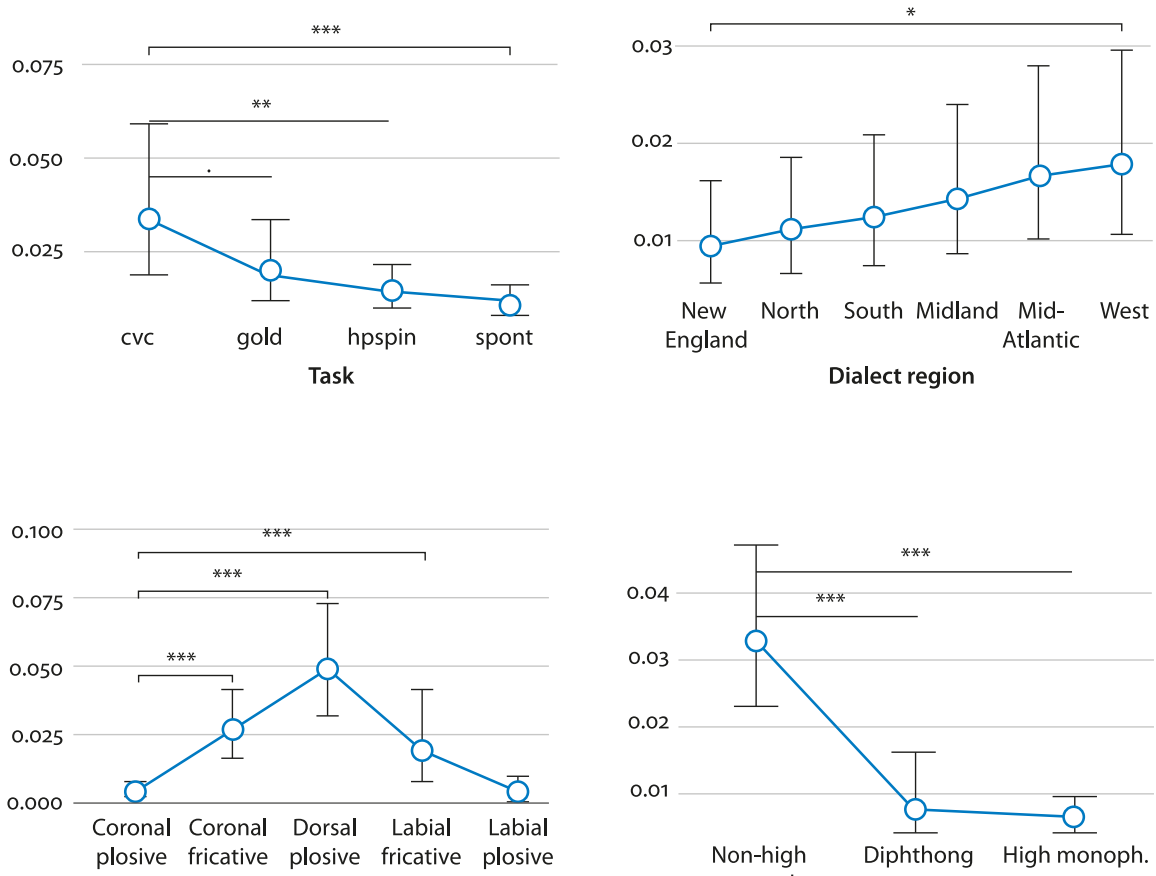

Following place and manner

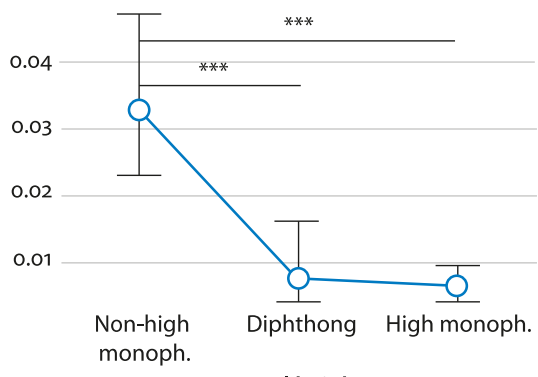

Vowel height

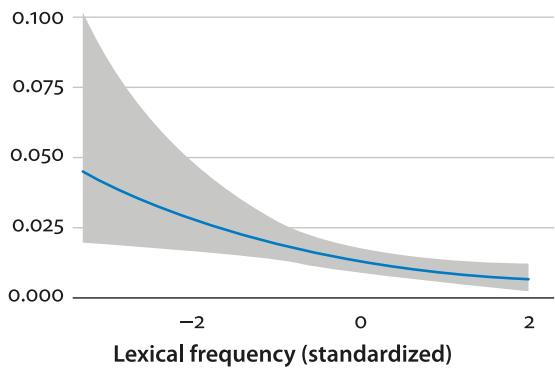

Figure 4. Partial effect plots of the significant terms of the model estimated with the effects package (Fox and Weisberg 2019) (variation in fixed effects, but not in random effects taken into account). Error bars and grey bands are 95 percent confidence intervals. The vertical axis in each plot shows probabilities

found that pre-aspiration does indeed occur in AmE (RQ1) with the frequency of 6 percent on average. AmE is therefore another variety where pre-aspiration is attested, making the phenomenon a fairly widespread feature of the Anglophone world. Considering that it occurs in Australia, the British Isles, Canada, New Zealand, and the US, it is possible that its presence in the language predates 
the period of colonization. This would be in line with the fact that, throughout its pre-colonisation history, English came into contact with Celtic and Scandinavian languages, which are all pre-aspirating (e.g. Ní Chasaide 1985; Helgason 2002; Morris 2010; Morris and Hejná 2020). Testing this hypothesis may nevertheless be impossible. Considering that pre-aspiration is a phenomenon notoriously below the speakers' (and often the linguists') awareness, a lack of any spelling evidence in Old English and Middle English manuscripts suggesting its presence would not necessarily imply that pre-aspiration was not present in the language in either of these periods. Another possibility is, as always, independent innovation.

We also report regional differences in AmE (RQ2). We find that the West is associated with the highest frequency of pre-aspiration application, although the difference is significant only when compared to New England. Only the North shows total absence of the phenomenon, and this absence is restricted to the spontaneous speech task context. In other cases, pre-aspiration is found in the range of 2-2o percent of cases, depending on the region and the task at hand. The phenomenon is regionally fairly consistent in the sense that most of the individuals produce it across and within region, without there being a handful of strongly pre-aspirating individuals skewing the average distributions. In fact, only two of the sixty speakers never show any pre-aspiration.

Our discussion of regional differences would not be complete without a discussion of the speaking tasks used in different English pre-aspiration studies (RQ4). The six regions show comparable effects of speaking task on the rate of application of pre-aspiration, which points to yet another regional consistency related to the production of the phenomenon. Similarly to Fiasson (2016), we report that pre-aspiration is indeed sensitive to speaking task, being most frequent in word-list data, and decreasing as we move on to a narrative passage, read sentences, and finally (semi-)spontaneous speech (wordlist > narrative passage, read sentences $>$ spontaneous speech). This finding is crucial for future work on pre-aspiration: researchers need to pay careful attention to the type of data used in pre-aspiration studies. This practical implication aside, our findings beg the question of why pre-aspiration should be most frequent in word-list data. We would like to suggest that this may be linked to the segmental and prosodic constraints on pre-aspiration and other phenomena affecting some types of obstruents, at least to some extent, and that crucially this depends on the variety in question. Before we provide the rationale behind this proposal however, it is important to discuss the implications of the results relevant for $\mathrm{RQ}_{3}$ : does AmE pre-aspiration occur in fortis fricatives /f, $\theta, \mathrm{s}, \mathrm{f} /$ as well as fortis plosives $/ \mathrm{p}, \mathrm{t}, \mathrm{k} /$ ?

We found that, for labials and coronals, pre-aspiration is most frequent in the fricative context as opposed to the plosive context (RQ3). This is in agreement with the findings available for Scottish Standard English (Gordeeva and Scobbie 
2013) and Manchester English (Hejná and Scanlon 2015), but not Aberystwyth English, mid Wales (Hejná 2015). What can explain these differences? We propose that this is due to the interaction with other processes affecting plosive obstruents, but not necessarily fricative obstruents, in specific varieties of English. Thus, glottalisation of plosives (e.g. pat [ $\mathrm{p}^{\mathrm{h}} \mathrm{a}$ ] $)$ found in Scottish Standard English blocks and bleeds pre-aspiration. On the other hand, we find pre-aspiration in the fricative context in the variety (where glottalling does not take place). Similarly, Hejná and Scanlon (2015) report glottalisation in foot-final plosives, where preaspiration does not occur, but they importantly find pre-aspiration in foot-final fricatives, which are not associated with glottalisation. The case of Aberystwyth English is different in that, on the whole, glottalisation is very infrequent (Hejná 2015). In other words, pre-aspiration may end up being more frequent in the fricative contexts in Scottish Standard English and Manchester English because it is blocked by glottalisation in the plosive contexts, rather than due to any articulatory and aerodynamic constraints on pre-aspiration (see e.g. Morris and Hejná 2020 for a discussion of these). The case of AmE is most likely not too dissimilar from those of Scottish Standard English and Manchester English. Firstly, /t/ is well-known to exhibit flapping. Although we excluded flapping contexts from the present study, from a separate analysis of one of the tasks (spont), we confirm that flapping bleeds pre-aspiration in 99 percent of cases. In addition, Eddington and Channer (2010) report the presence of glottalisation in a range of AmE accents, which presumably also blocks pre-aspiration, but importantly not in the fricative environment.

Segmental and prosodic factors thus interact in varieties of English when it comes to variation in fortis obstruents. In British English at least, these interactions are further conditioned by the nature of the speaking task. Glottalling is more frequent in spontaneous speech in British English more generally (e.g. Schleef 2013), and knowing that this phenomenon blocks pre-aspiration (Gordeeva and Scobbie 2013; Hejná and Scanlon 2015), we can predict that preaspiration should be less frequent in more informal speaking tasks in British English varieties (at least unless they show obligatory glottalling even in more formal tasks). Another, additional, suggestion, which may apply to our AmE data, is one already proposed by Steriade (1998:214) and Hejná and Jespersen (2019): pre-aspiration is preferred in prosodically more prominent contexts. Importantly, word-list data and isolated sentences can be expected to show more prosodic prominence. That this is not too far from the right track is confirmed by the fact that the second most frequently pre-aspirated words in the spontaneous task was 
yes (after week), ${ }^{4}$ which is often found as a single utterance, similarly to the words in the word-list task.

Prosodic prominence is nevertheless only one of at least three possible explanations as to why pre-aspiration is the least frequent in spontaneous speech in our dataset. It may be the case that the faster the speaking rate, the less prominent the pre-aspiration, potentially not applying at all, or less, in a faster tempo type of speech. Spontaneous speech is likely to offer a higher speaking rate than narrative passages and isolated high probability sentences, which are in turn likely to be associated with a higher speaking rate than words read in isolation. Finally, we noticed a range of phenomena when coding the data, occurring primarily in spontaneous speech, such as spirantization. These phenomena may also block pre-aspiration. A future investigation would have to be conducted to shed light on to what extent other, lesser investigated processes may block pre-aspiration in the data analysed.

We would like to propose that this also fits in well with the results related to lexical frequency (RQ10): we found that the more frequent the word, the lower the likelihood of pre-aspiration application. Phenomena such as spirantization, which might block pre-aspiration, could be expected to be found particularly in frequent words in faster speaking rate conditions. This, too, is something to be tested in future research. Our frequency findings are thus not in agreement with the study of Aberystwyth English pre-aspiration carried out by Hejná (2015). The author nevertheless only used words uttered in isolation and in the carrier sentence Say X again., which may not be the main locus of lexical frequency effects. On the other hand, the lexical frequency effects in our dataset hold across the four tasks analyzed. It is also important to note that the spontaneous task analyzed here is the only task which contains extremely high frequency words, such as like (used not only as a verb, but also as a discourse marker, a preposition, and a conjunction). One may wonder whether what seems to be a task effect may in fact be a lexical frequency effect. This is not so, however. After excluding these highly frequent items (stopwords), we still find the same effects of speaking task on preaspiration application in the AmE data analysed here.

Turning now to the cross-linguistically reported constraints on preaspiration, we first report that no effect of sex/gender has been found in this study

4. The most frequently pre-aspirated word was the word week ( 38 percent, $N=6 / 16$ ), then yes ( 35 percent, $N=18 / 51$ ), Boston ( 25 percent, $N=4 / 16$ ), back (18 percent, $N=13 / 74$ ), festival (15 percent, $N=3 / 20$ ), nice (14 percent, $N=7 / 50$ ), classes (12 percent, $N=3 / 26$ ), last (12 percent, $N=3 / 26$ ), house (10 percent, $N=3 / 29$ ), class (9 percent, $N=3 / 32$ ), guess (7 percent, $N=6 / 82$ ), and lexical like (1 percent, $N=13 / 1,040$ ), including only those words that were pre-aspirated at least three times. 
(RQ5). This contrasts sharply with other studies of English pre-aspiration, which report females as more frequent pre-aspirators and/or those that pre-aspirate with longer durations (see Morris and Hejná 2020 for an overview). The main rationale behind the physiological hypothesis is that females are generally breathier than males and thus more prone to pre-aspiration. However, the lack of sex/ gender differences in our data may not be seen as completely in disagreement with other pre-aspiration studies. In her Aberystwyth English data, Hejná (2015) does report the expected sex-related differences in pre-aspiration (females show more frequent pre-aspiration). However, these sex-related differences level out in apparent time, with the younger generations producing more frequent preaspiration than the older generations, with no sex effects found in the younger generations. The loss of sex/gender differences in "sound change from below" (where speakers are not consciously aware of the sound change in progress), with male speakers catching up with female speakers, has been identified and discussed by Labov (2010:255) as well as many others. It may be the case that pre-aspiration has been established in AmE long enough for sex-levelling to have taken place. Nonetheless, this interpretation is problematic, and the main problem is linked to the actuation and the incrementation problems: how long is long enough for sex/gender-differences to disappear in change from below?

Regarding language-internal constraints, the AmE data analysed here mainly shows tendencies similar to other pre-aspirating varieties of English, as well as other pre-aspirating languages. Addressing the effects of place of articulation first, we report that pre-aspiration occurs more frequently with $/ \mathrm{k} /$ than with $/ \mathrm{p} /$ (RQ6). The difference between $/ \mathrm{k} /$ and $/ \mathrm{p} /$ has been suggested to be due to articulatory and aerodynamic aspects of pre-aspiration (Morris and Hejná 2020). Cross-linguistically, / $\mathrm{k} /$ usually patterns with / $\mathrm{t} /$, or one of the two lags behind the other in a rather marginal way. Our AmE data however differs strikingly from other languages in that $/ \mathrm{t} /$ ( 2 percent) patterns with $/ \mathrm{p} /$ ( 3 percent) rather than $/ \mathrm{k} /$ (10 percent). The reason behind / $\mathrm{p} /$ exhibiting less pre-aspiration than $/ \mathrm{k} /$ that has been put forward (Morris and Hejná 2020) is that pre-aspiration is conditioned by the amount of post-aspiration: /p/ cross-linguistically shows shorter release durations than $/ \mathrm{t} /$ and $/ \mathrm{k} /$. It may therefore be the case that $/ \mathrm{t} /$ and $/ \mathrm{p} /$ have similar release duration, or are similar in showing less (noticeable) glottal friction, than $/ \mathrm{k} /$ in AmE. This line of thinking does indeed seem to be supported by the evidence available from other studies. For instance, Byrd (1993: 105) reports that the frequency of occurrence of a release is that of 49.5 percent for bilabial stops, 57 percent for alveolar stops, and 83.11 percent for velar stops. However, a more in-depth study needs to be conducted to test whether this may indeed explain the place of articulation effects reported here, especially since not 
all studies of AmE report the same place effects on release presence across the three places of articulation (see e.g. Davidson 2011).

Regarding the fricative results, our study adds to the rather limited knowledge about the effects of the place of articulation of the pre-aspiration-inducing fricative. /f/ and /s/ pattern together in conditioning 10 percent of pre-aspiration, with $/ \int /$ associated with only 2 percent and $/ \theta /$ with o percent. Hejná (2015:120) reports pre-aspiration occurring with all four of the places of articulation in her Aberystwyth English data. The analyses as presented by her allow us to compare our AmE results only to the finding that $/ \theta /$ is associated with higher pre-aspiration application than /f/, but no significant difference was found between /f/ and /s/ and $/ \mathrm{J} /$. This therefore seems contradictory to the situation apparent in the AmE data. Another regional difference is related to the fact that $/ \mathrm{s} /$ and $/ \mathrm{J} /$ are associated with much higher rates of pre-aspiration application in varieties of English spoken in the UK (e.g. Jones and Llamas 2003; Gordeeva and Scobbie 2010, 2013; Hejná 2015).

Apart from consonantal constraints, we also report three vocalic constraints on pre-aspiration in AmE, which are in line with what has been found crosslinguistically. Firstly, pre-aspiration is less frequent with high vowels and diphthongs than with non-high vowels (RQ7). This is in agreement with the general tendency for high vowels to disprefer pre-aspiration. Our findings nevertheless provide a novel insight by including diphthongs in the comparison, in contrast to the vast majority of pre-aspiration studies. Diphthongs pattern with high vowels in dispreferring pre-aspiration. Note that all our diphthongs end with a non-low glide. We also need to bear in mind however that diphthongs differ from monophthongs by aspects to do with moraicity rather than only vowel quality.

We also find that pre-aspiration is more likely to occur with phonologically lax rather than tense vowels (RQ8). Although other pre-aspiration studies employ the category of phonological length rather than tenseness (e.g. Hejná 2015: Chapter 4; these studies predominantly focus on British English), if we put length and tenseness on par for reasons of comparison, our result is in line with the general finding that pre-aspiration is more likely to occur with short rather than long vowels. Importantly, Present-Day English tense vowels originate in historically long vowels, and PDE lax vowels originate in short vowels.

Next, we find that for monosyllables, longer word durations are associated with higher likelihood of pre-aspiration. This suggests that pre-aspiration is more likely to occur with phonetically longer vowels (our RQ9). This result is therefore also in line with cross-linguistically reported tendencies. In this context, it is important to remember that phonetically longer vowels tend to occur in stronger prosodic positions, as well as in more formal speaking styles. Hence, teasing apart 
the effects of phonetic duration, prosodic strength, and task poses challenges that should be borne in mind in future research.

The study presented here concludes with the following further questions inspired by the results reported here:

- Q1: How old is pre-aspiration in AmE? Would apparent-time data show stable variation? How would the results of an apparent-time study fare with those available for Aberystwyth English, New Zealand English, and Tyneside English?

- Q2: How old is pre-aspiration in English? (This may not be an answerable question.)

- Q3: Does pre-aspiration have the same functions in different pre-aspirating varieties of English? Does it, for instance, participate as a correlate of the same phonological contrasts and allophonies? Does it do the same social work across different varieties of English? The structural functions of preaspiration across different English accents is a topic that has been touched upon, but it has not been taken up as a main research goal. While research on language-internal predictors of English pre-aspiration is somewhat dormant, the research into the social functions of English pre-aspiration has not even commenced.

- Q4: Other than flapping, do other phenomena bleed pre-aspiration in AmE (and other varieties of English as well)?

Closing with these four questions, we would like to invite the reader to help shed light on this fascinating phenomenon in various English accents.

\section{Acknowledgements}

We would like to thank Maria Grifoll Nogués, Melita Smolko, and Miriam Espinoza for the enthusiasm they showed, together with Wenyu Guo, when working on a class project in winter 2017, which involved analyzing pre-aspiration in a small subset of the Nationwide Speech Project corpus. This proved useful with inter-coder reliability between the first and the third author, but crucially also stimulated a lot of discussion that fed into some of the issues considered in the present paper. We also wish to thank Matteo Fuoli for his thoughts on our approach to inter-rater agreement. Our thanks also go to the audience of NWAV48 taking place in Eugene, Oregon, in 2019. All remaining errors are our own. 


\section{Sources}

Clopper, Cynthia G., and David B. Pisoni. 2006. “The Nationwide Speech Project: A New Corpus of American English Dialects." Speech Communication 48: 633-644. https://doi.org/10.1016/j.specom.2005.09.010

\section{References}

Bates, Douglas, Martin Maechler, Ben Bolker, and Steve Walker. 2015. "Fitting Linear MixedEffects Models Using lme4". Journal of Statistical Software 67: 1-48. https://doi.org/10.18637/jss.v067.io1

Benoit, Kenneth, David Muhr, and Kohei Watanabe. 2020. Stopwords: Multilingual Stopword Lists. $R$ package version 2.o. <https://CRAN.R-project.org/package=stopwords $>$

Boersma, Paul, and David Weenink. 2018. Praat: Doing Phonetics by Computer. Version 6.0.41, <http://www.praat.org/> (accessed August 15, 2018).

Brysbaert, Marc, and Borris New. 2009. "Moving Beyond Kučera and Francis: A Critical Evaluation of Current Word Frequency Norms and the Introduction of a New and Improved Word Frequency Measure for American English”. Behavior Research Methods 41(4): 977-990. https://doi.org/10.3758/BRM.41.4.977

Byrd, Dani. 1993. “54,000 American Stops”. UCLA Working Papers in Phonetics 83: 97-115. Clayards, Meghan, and Thea Knowles. 2015. "Prominence Enhances Voiceless-ness and Not Place Distinction in English Voiceless Sibilants". In The Scottish Consortium, eds. Proceedings of the 18th International Congress of Phonetic Sciences, Glasgow. <https:// www.internationalphoneticassociation.org/icphs-proceedings/ICPhS2015/proceedings .html> (accessed September 1, 2015).

Clayton, Ian. 2017. "Preaspiration in Hebrides English". Journal of the International Phonetic Association 47: 155-181. https://doi.org/10.1017/S002510031700007X

Clopper, Cynthia G., and Janet B. Pierrehumbert. 2008. "Effects of Semantic Predictability and Regional Dialect on Vowel Space Reduction". The Journal of the Acoustical Society of America 124(3): 1682-1688. https://doi.org/10.1121/1.2953322

Davidson, Lisa. 2011. "Characteristics of Stop Releases in American English Spontaneous Speech”. Speech Communication 53: 1042-1058. https://doi.org/10.1016/j.specom.2011.05.010

Docherty, Gerald, and Paul Foulkes. 1999. "Sociophonetic Variation in 'Glottals' in Newcastle English.” In John J. Ohala, Yoko Hasegawa, Manjari Ohala, Daniel Granville, and Ashlee C. Bailey, eds. Proceedings of the 14th International Congress of Phonetic Sciences, San Francisco, 1037-1040. <https://www.internationalphoneticassociation.org/icphsproceedings/ICPhS1999/papers/p14_1037.pdf> (accessed September 1, 2015).

Eddington, David, and Caitlin Channer. 2010. "American English Has Go? a Lo? of Glottal Stops: Social Diffusion and Linguistic Motivation”. American Speech 85: 338-351. https://doi.org/10.1215/00031283-2010-019

Fiasson, Romain. 2016. "Frication, Pre-aspiration and Tapping of Medial /t/ in New Zealand English". Te Reo 59: 47-69.

Fleiss, Joseph L. 1981. Statistical Methods for Rates and Proportions (2nd ed.). New York: John Wiley. 
Fox, John, and Sanford Weisberg. 2019. An R Companion to Applied Regression (3rd ed.). Thousand Oaks, CA: Sage. <https://socialsciences.mcmaster.ca/jfox/Books/Companion /index.html > (accessed October 1, 2019).

Fromont, Robert, and Jennifer Hay. 2012. "LaBB-CAT: An Annotation Store”. In Paul Cook and Scott Nowson, ed. Proceedings of the Australasian Language Technology Association Workshop, Dunedin, 113-117. https://www.aclweb.org/anthology/volumes/U12-1/ (accessed February 10, 2021).

Gordeeva, Olga, and James M. Scobbie. 2010. "Preaspiration as a Correlate of Word-Final Voice in Scottish English Fricatives”. In Susanne Fuchs, Martine Toda, and Marzena Żygis, eds. Turbulent Sounds: An Interdisciplinary Guide. Berlin: Mouton de Gruyter, 167-207. https://doi.org/10.1515/9783110226584.167

Gordeeva, Olga, and James M. Scobbie. 2013. "A Phonetically Versatile Contrast: Pulmonic and Glottalic Voicelessness in Scottish English Obstruents and Voice Quality". Journal of the International Phonetic Association 43: 249-271.

https://doi.org/10.1017/S0025100313000200

Hejná, Míša. 2015. "Pre-Aspiration in Welsh English: A Case Study of Aberystwyth”. Ph.D. Dissertation, University of Manchester.

Hejná, Míša. 2016a. "Multiplicity of the Acoustic Correlates of the Fortis-Lenis Contrast: Plosives in Aberystwyth English". In International Speech Communication Association, eds. Proceedings of the 17th Annual Conference of the International Speech Communication Association (Interspeech 2016), San Francisco: 3147-3151. <http://www.proceedings.com /32771.html> (accessed September 8, 2016).

Hejná, Míša. 2016b. "Pre-aspiration: Manual on Acoustic Analysis 1.1”. Manuscript released on LingBuzz, <https://ling.auf.net/lingbuzz/oo3184> (accessed September 23, 2019).

Hejná, Míša, and Anna B. Jespersen. 2019. "Focus on Consonants: Prosodic Prominence and the Fortis-Lenis Contrast in English”. In Anne Mette Nyvad, Mísa Hejná, Anders Højens, Anna B. Jespersen, and Mette Hjorten Sørense, eds. A Sound Approach to Language Matters. In Honor of Ocke-Schwen Bohn. Aarhus: Aarhus University, 237-270.

Hejná, Mîša, and Jane Scanlon. 2015. “New Laryngeal Allophony in Manchester English”. In The Scottish Consortium, eds. Proceedings of the 18th International Congress of Phonetic Sciences, Glasgow. <https://www.internationalphoneticassociation.org/icphs-proceedings /ICPhS1999/papers/p14_1037.pdf> (accessed September 1, 2015).

Helgason, Pétur. 2002. "Preaspiration in the Nordic Languages. Synchronic and Diachronic Aspects”. Ph.D. Dissertation, Stockholm University.

Jatteau, Adèle, and Míša Hejná. 2018. "Gradient Dissimilation in Halh Mongolian: Implication for Diachrony”. Papers in Historical Phonology 3: 28-75. https://doi.org/10.2218/pihph.3.2018.2821

Jones, Mark J., and Carmen Llamas. 2003. "Fricated Pre-aspirated /t/ in Middlesbrough English: An Acoustic Study”. In Maria-Josep Solé, Daniel Recasens, and Joaquín Romero, eds. Porceedings of the 15th International Congress of Phonetic Sciences, Barcelona, 655-658. <https://www.internationalphoneticassociation.org/icphs/icphs2003> (accessed September 1, 2012)

Jones, Mark J., and Kirsty McDougall. 2009. "The Acoustic Character of Fricated /t/ in Australian English: A Comparison with /s/ and / $\int /$ ". Journal of the International Phonetic Association 39: 265-289. https://doi.org/10.1017/S0025100309990132

Kettig, Thomas. 2015. “The BAD-LAD Split: A Phonetic Investigation”. M.Phil Dissertation, University of Cambridge. 
Kingston, John. 1990. “Articulatory Binding”. In John Kingston, and Mary E. Beckman, eds. Papers in Laboratory Phonology I. Between the Grammar and the Physics of Speech. Cambridge: Cambridge University Press, 406-434. https://doi.org/10.1017/CBO9780511627736.023

Labov, William. 2010. Principles of Linguistic Change. Vol. 3: Cognitive and Cultural Factors. Oxford: Wiley-Blackwell. https://doi.org/10.1002/9781444327496

Labov, William, Sharon Ash, and Charles Boberg. 2006. The Atlas of North American English. Phonetics, Phonology and Sound Change. Berlin: Mouton de Gruyter.

McKenna, Edoardo. 2013. "The Origin of Consonantal Pre-aspiration in Gàidhlig, Icelandic and Faroese: A Discussion”. In Robert McColl Millar, and Janet Cruickshank, eds. After the Storm: Papers from the Forum for Research on the Languages of Scotland and Ulster Triennial Meeting, Aberdeen 2012. Aberdeen: Forum for Research on the Languages of Scotland and Ireland, 82-99.

Morris, Jonathan. 2010. "Phonetic Variation in Northern Wales: Preaspiration”. In Miriam Meyerhoff, Chie Adachi, Agata Daleszynska, and Anna Strycharz, eds. Proceedings of the Second Summer School of Sociolinguistics, The University of Edinburgh 14 - 20 June 2010. Edinburgh: University of Edinburgh. <http://orca.cf.ac.uk/64918/1/Jon .pdf> (accessed March 10, 2017).

Morris, Jonathan, and Míša Hejná. 2020. "Pre-aspiration in Bethesda Welsh: A Sociophonetic Analysis". Journal of the International Phonetic Association 50(2): 168-192. https://doi.org/10.1017/So025100318000221

Nance, Claire, and Jane Stuart-Smith. 2013. "Pre-Aspiration and Post-Aspiration in Scottish Gaelic Stop Consonants”. Journal of the International Phonetic Association 43: 129-152. https://doi.org/10.1017/S0025100313000042

Di Napoli, Jessica. 2015. "Glottalization at Phrase Boundaries in Tuscan and Roman Italian”. In Joaquín Romero, and María Riera, eds. The Phonetics-Phonology Interface. Representations and Methodologies. Amsterdam: John Benjamins, 125-148. https://doi.org/10.1075/cilt.335.07nap

Ní Chasaide, Ailbhe. 1985. "Preaspiration in Phonological Stop Contrasts”. Ph.D Dissertation, University College of North Wales.

R Core Team. 2019. R: A Language and Environment for Statistical Computing. R Foundation for Statistical Computing, Vienna, Austria. <https://www.r-project.org/> (accessed October 1, 2019).

Rosenfelder, Ingrid, Josef Fruehwald, Keelan Evanini, Scott Seyfarth, Kyle Gorman, Hilary Prichard, and Jiahong Yuan. 2014. Fave 1.2.2. < https://github.com/JoFrhwld/FAVE /tree/v1.2.2>

Rotondi, Michael A. 2018. KappaSize: Sample Size Estimation Functions for Studies of Interobserver Agreement. R package version 1.2. <https://cran.r-project.org/web/packages /kappaSize/kappaSize.pdf> (accessed October 1, 2019).

Schleef, Erik. 2013. "Glottal Replacement of /t/ in Two Capitals: Effects of Word Frequency and Morphological Compositionality". Language Variation and Change 25: 201-223. https://doi.org/10.1017/So954394513000094

Steriade, Donca. 1998. "Alternatives to Syllable-Based Accounts of Consonantal Phonotactics". In Osamu Fujimura, Brian D. Joseph and Bohumil Palek, eds. Proceedings of LP ‘ 98. Prague: The Karolinum Press, 205-245. 
Stevens, Mary. 2010. "How Widespread is Preaspiration in Italy? A Preliminary Acoustic Phonetic Overview”. In Susanne Schötz, and Gilbert Ambrazaitis, eds. Proceedings from Fonetik 2010, Lund, June 2-4, 2010. Lund: Lund University Centre for Languages and Literature, 97-102.

$\mathrm{Su}$, Venetia W.Y. 2007. "The gender variable in Australian English stop consonant production". Honours dissertation, University of Melbourne.

Tait, Casey, and Marija Tabain. 2016. "Patterns of Gender Variation in the Speech of Primary School-Aged Children in Australian English: The Case of /p t k/". In

Christopher Carignan and Michael D. Tylor, eds. Proceedings of the 16th Australian International Conference on Speech Science and Technology, (SST 2016), Parramatta, 65-68. <https://assta.org/sst-2016-proceedings/> (accessed September 1, 2017).

Watson, Kevin. 2007. “The Phonetics and Phonology of Plosive Lenition in Liverpool English”. Ph.D. Dissertation, University of Lancaster.

\section{Appendix}

Table 4 shows ten words with highest frequency counts according to SUBTLEX-US. All of them show extremely low pre-aspiration rates (in most cases o percent). The rightmost column shows estimated probability of pre-aspiration for each word when all categorical predictors are held at their reference levels and all continuous predictors at their means. Recall that the model intercept is -3.00201 (log-odds), which equals to the probability of 0.05 .

Table 4. Ten words with highest frequency counts according to SUBTLEX-US and preaspiration frequency counts

\begin{tabular}{llcccc}
\hline Rank & Word & $\begin{array}{c}\text { Log-frequency } \\
\text { (SUBTLEX-US) }\end{array}$ & $\begin{array}{c}\text { Random } \\
\text { aspirated }\end{array}$ & $\begin{array}{c}\text { intercept (log- } \\
\text { odds) }\end{array}$ & $\begin{array}{c}\text { Estimated probability } \\
\text { of pre-aspiration }\end{array}$ \\
\hline 1 & that & 13.487 & 0.00 & -0.05 & 0.05 \\
2 & what & 13.126 & 0.00 & -0.42 & 0.03 \\
3 & this & 12.916 & 0.01 & 0.43 & 0.07 \\
4 & not & 12.531 & 0.00 & -0.31 & 0.04 \\
5 & get & 12.362 & 0.00 & -0.83 & 0.02 \\
6 & but & 12.325 & 0.00 & -0.38 & 0.03 \\
7 & right & 12.228 & 0.00 & -0.16 & 0.04 \\
8 & like & 12.226 & 0.01 & -0.37 & 0.03 \\
9 & out & 12.192 & 0.00 & -0.60 & 0.03 \\
10 & up & 12.140 & 0.00 & -0.24 & 0.04 \\
\hline
\end{tabular}


Table 5 displays ten words with highest token counts (the $n$ column) in our dataset. Most of them show very low rates of pre-aspiration, ranging from o percent to 3.6 percent, with the exception of walk (26.49 percent). The rightmost column shows estimated probability of preaspiration for each word when all categorical predictors are held at their reference levels and all continuous predictors at their means. Recall that the model intercept is -3.00201 (log-odds), which equals to the probability of 0.05 .

Table 5. Ten words with highest frequency counts in our dataset and pre-aspiration frequency counts

\begin{tabular}{llcccc}
\hline Rank & Word & $n$ & $\begin{array}{c}\text { \% pre- } \\
\text { aspirated }\end{array}$ & $\begin{array}{c}\text { Random intercept } \\
\text { (log-odds) }\end{array}$ & $\begin{array}{c}\text { Estimated probability of } \\
\text { pre-aspiration }\end{array}$ \\
\hline 1 & like & 1040 & 1.25 & -0.37 & 0.03 \\
2 & that & 427 & 0.47 & -0.05 & 0.05 \\
3 & out & 373 & 0.00 & -0.60 & 0.03 \\
4 & cut & 239 & 0.00 & -1.43 & 0.01 \\
5 & took & 202 & 0.99 & -0.76 & 0.02 \\
6 & off & 194 & 3.61 & -0.60 & 0.03 \\
7 & that's & 190 & 1.05 & 0.01 & 0.05 \\
8 & walk & 185 & 26.49 & -0.25 & 0.04 \\
9 & got & 182 & 0.55 & -0.38 & 0.03 \\
10 & keep & 182 & 0.00 & -0.71 & 0.02 \\
\hline
\end{tabular}

\title{
Address for correspondence
}

\author{
Míša Hejná \\ Aarhus University \\ Department of English \\ Jens Chr. Skous Vej 4 \\ 8000 Aarhus C \\ Denmark \\ misa.hejna@cc.au.dk
}




\section{Co-author information}

Kamil Kaźmierski

Wydział Anglistyki UAM

Adam Mickiewicz University, Poznań

kamil.kazmierski@amu.edu.pl

\section{Publication history}

Date received: 8 April 2020

Date accepted: 14 October 2020

Published online: 26 April 2021
Wenyu Guo

Aarhus University

ideajoke@gmail.com 